\title{
VIGOTSKI E PAULO FREIRE: contribuições para a autonomia do professor
}

\author{
Vigotski and Paulo Freire: \\ contributions for the teachers' autonomy
}

\begin{abstract}
Ana Paula Petroni ${ }^{a}$, Vera Lúcia Trevisan de Souza ${ }^{\mathrm{b}}$
a Doutoranda da Pontifícia Universidade Católica de Campinas (PUCCAMP), bolsista Capes, Campinas, SP - Brasil, e-mail: paulinhapetroni@yahoo.com.br

b Professora do Programa de Pós-Graduação em Psicologia da Pontifícia Universidade Católica de Campinas (PUCCAMP), Campinas, SP - Brasil, e-mail: vera.trevisan@uol.com.br
\end{abstract}

\section{Resumo}

Este artigo tem por objetivo apresentar algumas reflexões sobre a autonomia docente da perspectiva da teoria de Vigotski (principal representante da Teoria Sócio-Histórica) e Paulo Freire (representante da Educação Libertadora). Essas reflexões são parte de uma pesquisa de Mestrado que está em desenvolvimento e tem por objetivo analisar, através das falas de professores, o que eles entendem por autonomia e se a autonomia encontra-se presente nas práticas pedagógicas que desenvolvem. Acreditamos ser possível aproximar esses dois autores por possuírem a mesma base epistemológica: o materialismo histórico-dialético; além de ambos tratarem da autonomia, ou autorregulação, para Vigotski, como sendo de máxima importância para o desenvolvimento do sujeito. Os autores fazem discussões, indo de acordo com suas bases, a respeito da influência do social, do cultural na formação de um sujeito autônomo. Abre-se aqui um

Rev. Diálogo Educ., Curitiba, v. 9, n. 27, p. 351-361, maio/ago. 2009 
espaço para Psicologia e educação trabalharem juntas, no coletivo, cada qual contribuindo para uma melhor relação entre os sujeitos.

Palavras-chave: Autonomia docente. Teorias sócio-históricas. Desenvolvimento humano. Autorregulação. Educação libertadora.

\section{Abstract}

This article aims to present some reflections about the autonomy of teaching from the perspective of the theory from Vigotski (main representative of the Socio-Historical theory) and Paulo Freire (representative of the Liberative Education). These reflections are part of a search of Masters which is under construction and aims to examine, by the words of teachers, what they mean by autonomy and if the autonomy is present in the teaching practices that they develop. We believe that we can bring these two authors nearer because they have the same epistemological base: the historical and dialectical materialism; farther on both treat about autonomy or self-regulation for Vigotski, as being of utmost importance for the development of the individual. The authors make discussions going in accordance with their bases, in relation to the influence of the social, from the cultural in the formation of an autonomous individual. Here opens up, a space for the psychology and the education to work together, in collective. Each one contributing for a better relationship between individuals.

Keywords: Teacher autonomy. Socio-historical theories. Human development. Self-regulation. Liberative education.

\section{INTRODUÇÃO}

Este artigo é parte de uma dissertação de Mestrado que está em desenvolvimento e tem por objetivo analisar, através das falas de professores, o que eles entendem por autonomia e se a autonomia encontra-se presente nas práticas pedagógicas que desenvolvem. A fundamentação teórica deste trabalho é a teoria sócio-histórica de Vigotski e a teoria da Educação Libertadora de Paulo Freire.

Acreditamos que essa aproximação seja possível devido à matriz teórica adotada pelos dois autores: o materialismo dialético. Sendo assim, o

Rev. Diálogo Educ., Curitiba, v. 9, n. 27, p. 351-361, maio/ago. 2009 
objetivo do presente texto é apresentar algumas das reflexões feitas a partir da teoria de Vigotski e Paulo Freire sobre o conceito de autonomia.

A autonomia é um tema que vem sendo bastante discutido nos dias de hoje, a nosso ver, devido aos novos caminhos que vem sendo tomados pela Educação. Vários trabalhos (BASSO, 1998; ARENDT, 2002; MARTINS, 2002; LÜDKE; BOING, 2004; SOUZA, 2005) tratam da autonomia do professor e da escola de diferentes perspectivas. De um modo geral, esses trabalhos buscam, ao definir o que seria a autonomia, uma forma de melhorar a educação, de melhorar as relações existentes no contexto escolar, de pensar no papel da escola e do professor na formação do aluno, de abolir o abuso da autoridade, que virou autoritarismo e afeta as relações dentro da escola, de reduzir a burocracia e a política como influência direta e, muitas vezes, negativa do trabalho, etc.

Podemos dizer que, atualmente, ao falarmos de autonomia, resvalamos em outros temas, como a heteronomia e a autoridade, já que a escola, e consequentemente o professor, tem assumido outras tarefas sem ser a de ensinar (seu principal papel em nosso entendimento). Cada vez mais o professor assume a função de educar as crianças em todos os sentidos. No entanto, ao mesmo tempo em que a escola e o professor assumem essas responsabilidades a eles delegadas pela sociedade em geral, eles são desacreditados, seu trabalho é posto em xeque e novas ações são impostas na tentativa de melhorar a qualidade da educação, sem que os maiores interessados sejam consultados.

Nos parece, se assim podemos chamar, uma bola de neve, pois as pressões vão vindo de cima e cada vez maiores, até chegar ao professor, que acabada agindo como agem com ele.

Diante deste quadro nos questionamos: como dizer que o professor precisa formar o aluno como cidadão autônomo, se muitas vezes ele próprio não pode exercer sua autonomia?

Essa questão não pode ser respondida de modo simplista. Ela demanda que se investigue a formação, tanto inicial quanto continuada, que vem sendo oferecida ao professor, as condições de trabalho a que ele está submetido, dentre tantos outros aspectos que envolvem o contexto docente em nosso país.

O que buscaremos, para os propósitos deste artigo, é buscar responder a seguinte questão: Como Vigotski e Paulo Freire podem contribuir para a compreensão da autonomia docente?

\section{Conhecendo e aproximando Vigotski e Paulo Freire}

Apesar de terem vivido em épocas e contextos diferentes, o pensamento de Freire e Vigotski se aproximam, e muito. Gadotti (1996) nos apresenta que foi

Rev. Diálogo Educ., Curitiba, v. 9, n. 27, p. 351-361, maio/ago. 2009 
somente no final de sua vida que Freire entrou em contato com a produção de Vigotski, mas que mesmo assim eles se assemelham em vários aspectos.

Mesmo a diferença entre os dois teóricos, apontada por Gadotti (1996), se constitui como razão para adotá-las como suporte às nossas investigações: enquanto a teoria de Vigotski se preocupa com o desenvolvimento psicológico do sujeito, Freire se volta aos aspectos pedagógicos, ou seja, à educação. Essa constatação nos leva a acreditar que se compreendemos a educação como prática social que tem como fim último promover o desenvolvimento humano, parece fértil adotar as ideias desses autores para explicar os fenômenos que pretendemos investigar.

A primeira aproximação dessas duas teorias está na base epistemológica. Ambos os autores se utilizam de conceitos do marxismo para fundamentarem seus postulados. Vigotski cunha do marxismo o uso de instrumentos para a transformação da natureza, a partir do que ele elabora a noção de signo e sua função na transformação do psiquismo humano. Toma como base o materialismo dialético e histórico para compreender o contexto e as ações do sujeito, entendendo o fenômeno psicológico como em constante movimento (PALANGANA, 1994; PINO, 2000; MARQUES; OLIVEIRA, 2005).

O método dialético de Marx contribuiu para a formulação da proposta de Freire com as ideias de práxis e de compreensão da luta de classes, da opressão exercida pela classe dominante à classe dominada, e da maneira como se dá o processo para que os oprimidos continuem na alienação (DAMKE, 1995; SANTOS, 2000).

Outro ponto de aproximação desses dois autores, assim como mostrado por Marques e Oliveira (2005), é a concepção do sujeito como histórico-cultural.

Vigotski acredita que o homem só se constitui mediado pela história. Logo, não deve ser deslocado de seu contexto para ser estudado, pois, ao longo de seu desenvolvimento, sofre influência da cultura e da história na qual está inserido (PALANGANA, 1994; PINO, 2000).

Do ponto de vista freiriano, o homem se encontra inserido em uma realidade social que deve ser utilizada como ponto de partida para a sua compreensão. O homem deve ser compreendido como uma totalidade e não como um sujeito isolado, em que pensar e agir criticamente a realidade na busca de transformá-la, faz parte da sua natureza, no caminho de sua humanização (FREIRE, 1999, 2005). Assim, o homem só se hominiza na medida em que se apropria da cultura.

Mais uma aproximação pode ser feita quanto à perspectiva interacionista. Tanto Freire quanto Vigotski acreditam que é na interação, nas relações sociais que os sujeitos se constituem e produzem conhecimento. Para reconhecer a si mesmo, o sujeito precisou, antes, estabelecer relações com outros (MARQUES; OLIVEIRA, 2005).

Rev. Diálogo Educ., Curitiba, v. 9, n. 27, p. 351-361, maio/ago. 2009 
Freire $(1996,1999,2005)$ entendia que por meio da união dos homens é que se constrói a possibilidade de mudança. A tomada de consciência se dá em um processo de interação entre os homens, na busca utópica de transformação da realidade que oprime, tornando-se assim viável e se apresentando como uma nova condição. Ou seja, é a partir do outro, da internalização da cultura mediada por esse outro, que o sujeito se constitui como singular.

Vigotski (1998) nos apresenta a sua ideia de interação ao pontuar que tudo o que constitui o sujeito já esteve antes no âmbito social, ou seja, antes de fazer parte do intrassubjetivo, os processos psicológicos fizeram parte da intersubjetividade. Esse movimento se dá pela via da internalização, que possibilita ao sujeito se apropriar do que existe no externo por meio da mediação de signos apropriados na relação com outros, para torná-la interna. Desta forma, o sujeito constrói a si e aos outros.

A importância dada ao diálogo por Freire e à linguagem por Vigotski, diz respeito a um outro estreitamento entre esses dois autores.

Vigotski (1991) dedicou sua obra Pensamento e Linguagem a essa questão da linguagem e de como ela influencia no desenvolvimento do pensamento. Para ele, seria por meio da linguagem que o sujeito teria a possibilidade de transformar o concreto em abstrato, de passar do âmbito do real para o simbólico, permitindo que o sujeito possa formular representações desse real. A linguagem é constituída socialmente, por isso carrega tudo o que há de produção na sociedade.

Já o diálogo, do ponto de vista de Freire $(1996,1999)$, é a fonte de comunicação entre os sujeitos, permite que se aproximem e expressem suas opiniões, estabelecendo, assim, uma relação bidirecional, em que ambos os sujeitos possam aprender e ensinar, promovendo o desenvolvimento da consciência crítica.

Vigotski e Freire também concordam na maneira como o conhecimento se constrói. Freire $(1996,1999,2005)$ postula que o conhecimento deve ser construído partindo-se da necessidade reconhecida no cotidiano do sujeito. A teoria deve ser construída tomando por base um problema localizado na prática, para então ser utilizada como luz para solucionar esse problema. Nas palavras de Marques e Oliveira (2005, p. 5) "[...] Conhecer, na teoria freireana, é uma aventura pessoal num contexto social."

Para Vigotski, o conhecimento se dá a partir do que é sabido pelo sujeito de seu cotidiano, do que ele internalizou ao longo de seu desenvolvimento, por meio das relações sociais estabelecidas, como produção cultural (PALANGANA, 1994; MARQUES; OLIVEIRA, 2005).

O ponto final desse caminho, tanto para Freire quanto para Vigotski, é o conhecimento científico (MARQUES; OLIVEIRA, 2005).

Uma última aproximação que nos interessa, é que ambos consideram que o modo como se dá a educação não é adequado. Denominada por Freire de

Rev. Diálogo Educ., Curitiba, v. 9, n. 27, p. 351-361, maio/ago. 2009 
educação bancária e por Vigotski de velha escola, eles apresentam concepções que se opõem à simples transmissão de conhecimento, ao modo de ver o sujeito como individual, a-histórico, como se o seu saber também não fosse cultural e ele não estivesse inserido em uma sociedade (MARQUES; OLIVEIRA, 2005).

Podemos ver, então, que as ideias de Vigotski e Freire muito se assemelham e podem se constituir em fundamento das análises desse trabalho. Inclusive porque pretendemos propor uma aproximação entre os conceitos de autorregulação de Vigotski e autonomia de Paulo Freire. Ambos acreditavam que o caminho para a humanização, para a ação consciente passava pela liberdade de escolha, pela responsabilidade na tomada de decisões. Chegamos ao objetivo deste texto: como Vigotski e Paulo freire entendiam a autonomia.

Vigotski (1995) denominava este processo de autorregulação, a função psicológica superior mais importante, já que ela permite que o sujeito tenha controle sobre as outras funções psicológicas ao dominar sua conduta. Para ele, o sujeito constitui-se como autorregulado no momento em que consegue internalizar as regras, as normas, os costumes existentes no meio ao qual pertence. Esse processo se dá desde seu nascimento, pois, como já dito antes, ao nascer, a criança já se encontra em uma cultura e através da mediação do outro exercida pela linguagem (fala, gestos, etc.) vai controlando seu comportamento de acordo com o que lhe é significado.

O processo de autorregulação se desenvolve em quatro estágios: primeiramente, o comportamento da criança é regulado pelo adulto, por meio de estímulos concretos e imediatos, obedecendo às leis do estímulo-resposta; o segundo estágio ocorre quando a criança adquire alguma capacidade de mediação, já que o seu comportamento ainda é afetado somente por estímulos concretos e reais, que tenham ligação com o externo; o estágio seguinte se inicia quando a criança começa, a partir de sua experiência, a regular suas ações com a manipulação de sinais, mas ainda há limitações, pois depende fortemente dos estímulos externos; por fim, o quarto estágio, é aquele em que a criança internaliza (interioriza) as relações sociais e passa a agir sem a ajuda direta dos estímulos externos para chegar a uma resposta (DÍAZ; NEAL; AMAYA-WILLIAMS, 1996).

Diaz, Neal e Amaya-Willians (1996) trazem que um outro aspecto que deve receber atenção no desenvolvimento da autorregulação é o processo social, já que, por meio das interações estabelecidas, a criança vai internalizando os signos auxiliares utilizados pelo outro para controlar seu comportamento, e passa a utilizá-los também para que possa controlar a ação desse outro. Nesse processo, a palavra passa a ser o signo mais utilizado para significar e mediar as relações entre a criança e o outro, de maneira compartilhada, tentando dominar o ambiente no qual está inserida. O discurso da criança passa a ter a função de mediar suas interações sociais e guiar suas atividades.

Rev. Diálogo Educ., Curitiba, v. 9, n. 27, p. 351-361, maio/ago. 2009 
A partir das considerações feitas acima, poderíamos dizer que a autorregulação é o resultado da mediação realizada nas e pelas interações sociais das características culturais presentes no contexto em que o sujeito está inserido, e que foram significadas e tornadas suas pela atribuição de sentidos pelo sujeito, permitindothe construir e dominar sua conduta. Ela seria a capacidade adquirida pelo sujeito de se autorregrar, ou seja, a partir do momento em que ele internalizou as regras mediadas pelo outro e significou-as para si, atribuiu um sentido próprio a elas, tornando-as internas, ele consegue formular suas próprias regras que possam autorregulá-lo.

Freire $(1996,1999,2005)$ trabalhava com o conceito de autonomia como a capacidade de agir por si, de poder escolher e expor ideias, agir com responsabilidade. Essas definições demonstram a semelhança dos conceitos.

$\mathrm{O}$ autor tem uma obra dedicada somente a este conceito: Pedagogia da autonomia (1996), que nos mostra bem a sua posição e o trabalho que deve ser desenvolvido pelo educador que trabalha nessa perspectiva.

Ao ler essa obra, compreendemos que autonomia corresponde à capacidade do sujeito de tomar decisões, de ser responsável pelos seus atos, de saber-se no mundo de maneira crítica, de ter dignidade. Para ele, a autonomia se desenvolve por meio da educação.

O educador que se propõe a trabalhar na perspectiva realmente progressista está se dispondo a reconhecer-se como parceiro de seu aluno e a promover desenvolvimento. Ele se submete a tudo aquilo que envolve o processo de ensinar, assim como apontado por Freire (1996), e que ao final resultará em uma formação, dele e de seu aluno, libertária e autônoma.

Nesse sentido, compreendemos que, ao exercer uma prática crítica, consciente, respeitando as diferenças, a autonomia, estimulando a curiosidade, relacionando teoria e prática, exercendo a pesquisa, agindo com humildade e tolerância, sabendo-se inacabado, respeitando os saberes e a identidade cultural de cada um, com coerência, escutando e dialogando com os educandos, libertária e autonomamente, etc., o educador possibilitará uma formação que promoverá o desenvolvimento dessas mesmas dimensões.

$\mathrm{Na}$ medida em que necessita estar atento ao que acontece com seus alunos, ser crítico para formar críticos, ser livre para promover libertação, ser consciente para superar a alienação, acreditar na mudança para promover transformações, refletir sobre sua prática à luz de uma teoria, não desprezar os saberes e a cultura de cada um, respeitar para ser respeitado, e o aspecto que mais nos interessa nesse trabalho, ser autônomo para formar para a autonomia, caminhando para o processo natural de humanização (FREIRE, 1996, 1999, 2005).

Com as reflexões teóricas apresentadas aqui, a aproximação que fazemos entre a autonomia, objeto de estudo deste trabalho, e a autorregulação é que ambas dizem respeito ao autodomínio, à liberdade que o sujeito adquire para agir de acordo

Rev. Diálogo Educ., Curitiba, v. 9, n. 27, p. 351-361, maio/ago. 2009 
com suas próprias leis, partindo do que já existe dentro da sociedade e da cultura na qual está inserido, mas sem deixar de lado a responsabilidade por suas ações e compreender que qualquer que seja a atitude tomada há de se ter criticidade.

Não podemos nos esquecer, também, do social, do cultural, tão importantes nas obras desses dois autores e que se constituem como peças essenciais para o desenvolvimento de um sujeito autônomo. As influências do meio têm papel importante na constituição da autonomia, já que é nesse espaço que se abrem oportunidades de o sujeito exercer suas ações com responsabilidade.

\section{CONSIDERAÇÕES FINAIS}

Pensar na autonomia docente não é tarefa fácil e nem se esgota nas reflexões aqui apresentadas. O trabalho do professor deve ser visto de forma ampla e completa, com todas as influências que o cercam: política, instituição, alunos, outros profissionais, etc.

Vigotski e Paulo Freire nos põem para refletir sobre essas influências, em como o meio é fundamental para a constituição do sujeito, ao mesmo tempo em que esse sujeito também constitui o meio: meio autônomo-sujeito autônomo.

Pudemos observar que esses dois autores, mesmo tendo vivido em contextos totalmente diferentes, possuem muitas coisas em comum, inclusive o objeto de estudo desta pesquisa: a autonomia. Ambos se preocuparam com a forma como os sujeitos são formados, constituídos e, ao mesmo tempo, constituem a cultura, o conhecimento, a sociedade em geral.

Da perspectiva de Vigotski (1995), pode-se compreender que para o sujeito tornar-se capaz de dominar sua própria conduta, é preciso passar pelo complexo desenvolvimento das funções psicológicas elementares às superiores, caminho que é percorrido via mediação do outro, pelo desenvolvimento da fala, já que a linguagem é considerada como o principal meio de aquisição e internalização dos signos existentes na cultura.

O sujeito constitui-se como autorregulado no momento em que consegue internalizar as regras, as normas, os costumes existentes no meio ao qual pertence. Esse processo se dá desde seu nascimento, pois, como já dito antes, ao nascer, a criança já se encontra em uma cultura e através da mediação do outro exercida pela linguagem (fala, gestos, etc.) vai controlando seu comportamento de acordo com o que lhe é significado (VIGOSTKI, 1995).

Assim, à medida que o sujeito vai se constituindo, de acordo com o que lhe é significado pelos outros, vai produzindo seus próprios significados e assumindo o controle voluntário de seu comportamento. A linguagem não deixa

Rev. Diálogo Educ., Curitiba, v. 9, n. 27, p. 351-361, maio/ago. 2009 
de existir, mas ela deixa de ser somente externa e exercida pelo outro, para se tornar interna, exclusiva daquele sujeito, que agora se torna capaz de se regular e tomar decisões, já que internalizou as normas e regras do social (PINO, 2000; SOUZA, 2005).

Em Paulo Freire (1996, 1999, 2005), o conceito de autonomia é compreendido como um processo resultante do desenvolvimento do sujeito, que se relaciona ao fato dele tornar-se capaz de resolver questões por si mesmo, de tomar decisões sempre de maneira consciente e pronto para assumir uma maior responsabilidade e arcar com as consequências de seus atos.

De acordo com Freire $(1996,1999,2005)$, esse modelo de educação se contrapõe à reprodução da cultura dominante, respeitando a individualidade, a história de cada um, proporcionando a aquisição de conhecimentos, mas levando em consideração o que já era sabido pelo aluno. Para isso, o professor também, deve estar consciente de sua história, da cultura da qual é representante e adotar uma prática pedagógica autônoma.

Logo, para que o professor seja capaz de desempenhar esse papel é necessário que ele na só tenha autonomia enquanto liberdade de ação, mas também que a compreenda como necessária ao desenvolvimento de práticas educacionais mais efetivas, ou seja, visto que os sentidos e significados atribuídos a ela interferem em sua maneira de agir.

Entendemos, assim, que não basta a escola ou a educação abrir espaços de atuação dos sujeitos - alunos e professores, por exemplo. É preciso que se forme para a autonomia, que se promovam mediações capazes de favorecer a conscientização do que se faz e do porquê se faz.

Daí a importância de, além de observar as relações na escola, buscando identificar a presença ou ausência da autonomia dos atores em relação, investigar os sentidos e significados da autonomia para esses atores.

Compreendemos que a autonomia seja mais uma questão da Educação que abre espaço para um trabalho conjunto com a Psicologia, já que se fazem presentes as subjetividades produzidas nas e pelas relações estabelecidas entre os atores escolares, e para o nosso interesse, o professor.

Escolhemos o professor por acreditar que ele seja uma das portas de entrada para a escola, já que ele vem se constituindo como o profissional que não é escutado e frequentemente colocado em xeque. Suas questões e opiniões não são levadas em consideração e elas acabam sendo encobertas pelas imposições existentes.

Para finalizarmos, ainda refletindo sobre a autonomia, deixamos algumas questões que poderão servir a pesquisas futuras: como melhorar, ou melhor, promover a autonomia do professor? Como conscientizá-lo para que ele possa conscientizar seu aluno? Qual o papel da sociedade nesse contexto?

Rev. Diálogo Educ., Curitiba, v. 9, n. 27, p. 351-361, maio/ago. 2009 


\section{REFERÊNCIAS}

ARENDT, H. Entre o passado e o futuro. Tradução de Mauro W. Barbosa de Almeida. São Paulo: Perspectiva, 2002.

BASSO, I. S. Significado e sentido do trabalho docente. Caderno CEDES, v. 19, n. 44, 1998. Disponível em: <http://www.scielo.br/scielo.php?script=sci artttext\&pid=S0101-32621998000100003\&Inh=pt\&nrm=iso > . Acesso em: 16 abr. 2007.

DAMKE, I. R. O processo do conhecimento na pedagogia da libertação: as idéias de Freire, Fiori e Dussel. Petrópolis: Vozes, 1995.

DÍAZ, R. M.; NEAL, C. J.; AMAYA-WILLIAMS, M. As origens sociais da auto-regulação. In: MOLL, L. C. Vygotsky e a educação. Porto Alegre: Artmed, 1996. p. 123-149.

FREIRE, P. Pedagogia da autonomia: saberes necessários à prática educativa. 35. ed. São Paulo: Paz e Terra, 1996.

. Educação como prática da liberdade. 23. ed. Rio de Janeiro: Paz e Terra, 1999.

. Pedagogia do oprimido. 41. ed. Rio de Janeiro: Paz e Terra, 2005.

GADOTTI, M.; FREIRE, P. A prática à altura do sonho. Disponível em: <www.antroposmoderno.com/textos/freire.shtml>. Acesso em: 29 set. 2007.

LÜDKE, M.; BOING, L. A. Caminhos da profissão e da profissionalidade docentes. Educação \& Sociedade, v. 25, n. 89, p. 1159-1180, set./dez. 2004. Disponível em: <http://www.scielo.br/scielo.php?script=sci_arttext\&pid= S0101-73302004000400005\&lng=pt\&nrm=iso>. Acesso em: 16 abr. 2007.

MARQUES, L. P.; OLIVEIRA, S. P. P. Paulo Freire e Vygotsky: reflexões sobre a educação. In: COLÓQUIO INTERNACIONAL PAULO FREIRE, 5., 2005, Recife. Memórias dos Colóquios on-line... Recife: [s.n.], 2005. Disponível em: <http://www.paulofreire.org.br/pdf/comunicacoes_orais/ P A U L O \% 20 F R E I R E \% 20 E \% 20 V Y G O T S K Y \%20REFLEX\%C3\%95ES\%2 0S OBRE\%20A\%20EDUCA\%C3\% 87\%C3\%83O.pdf>. Acesso em: 05 ago. 2007.

Rev. Diálogo Educ., Curitiba, v. 9, n. 27, p. 351-361, maio/ago. 2009 
MARTINS, A. M. Autonomia e educação: a trajetória de um conceito. Cadernos de Pesquisa, n. 115, p. 207-232, mar. 2002. Disponível em: <http://www.scielo. br/ scielo.php?script=sci_arttext\&pid=S010015742002000100009\&lng=pt\&nrm=iso $>$. Acesso em: 16 abr. 2007.

PALANGANA, I. S. Desenvolvimento \& aprendizagem e Piaget e Vigotski: a relevância social. São Paulo: Plexus, 1994.

PINO, A. O social e o cultural na obra de Vigotski. Educação e Sociedade, Campinas, v. 21, n. 71, p. 45-78, 2000. Edição especial.

SANTOS, A. F. T. dos. Desigualdade social e dualidade escolar: conhecimento e poder em Paulo Freire e Gramsci. Petrópolis: Vozes, 2000.

SOUZA, V. L. T. Escola e construção de valores: desafios à formação do aluno e do professor. São Paulo, Loyola, 2005.

VIGOTSKI, L. S. Obras escogidas III: problemas del desarrollo de la psique. Visor Distribuciones: Madrid, 1995.

A formação social da mente: o desenvolvimento dos processos psicológicos superiores. Tradução de José Cipolla Neto, Luís Silveira Menna Barreto e Solange Castro Afeche. 6. ed. São Paulo: Martins Fontes, 1998.

Recebido: 27/06/2008

Received: 06/27/2008

Aprovado: $01 / 08 / 2008$

Approved: 08/01/2008

Revisado: 21/07/2009

Reviewsed: 07/21/2009

Rev. Diálogo Educ., Curitiba, v. 9, n. 27, p. 351-361, maio/ago. 2009 